Article

\title{
Influence of Grit-Blasting and Hydrofluoric Acid Etching Treatment on Surface Characteristics and Biofilm Formation on Zirconia
}

\author{
Aifang Han ${ }^{1,2}$, James K.-H. Tsoi ${ }^{1, *}{ }^{(\mathbb{D})}$, Jukka P. Matinlinna ${ }^{1}$ and Zhuofan Chen ${ }^{2,3, *}$ \\ 1 Dental Materials Science, Faculty of Dentistry, The University of Hong Kong, Hong Kong, China; \\ aifanghan@hotmail.com (A.H.); jpmat@hku.hk (J.P.M.) \\ 2 Guangdong Provincial Key Laboratory of Stomatology, Sun Yat-sen University, Guangzhou 510275, China \\ 3 Department of Oral Implantology, Hospital of Stomatology, Guanghua School of Stomatology, \\ Institute of Stomatological Research, Sun Yat-sen University, Guangzhou 510275, China \\ * Correspondence: jkhtsoi@hku.hk (J.K.-H.T.); dentistczf@163.com (Z.C.); \\ Tel.: +852-2859-0303 (J.K.-H.T.); +86-20-8386-3002 (Z.C.)
}

Received: 23 June 2017; Accepted: 16 August 2017; Published: 20 August 2017

\begin{abstract}
The objective of this study was to investigate the effect of hydrofluoric acid etching treatment on the surface characteristics of zirconia and Streptococcus sanguinis (S. sanguinis) and Porphyromonas gingivalis (P. gingivalis) biofilm formation on zirconia. Zirconia specimens were prepared with different treatments, including being polished with 1000-grit SiC abrasive paper as the control group (Group C), grit-blasted with $110 \mu \mathrm{m}$ silica-coated alumina particles (Group GB), etched with $40 \%$ hydrofluoric acid for $25 \mathrm{~min}$ at $100{ }^{\circ} \mathrm{C}$ (Group HF), and grit-blasted with $110 \mu \mathrm{m}$ silica-coated alumina particles and then etched with $40 \%$ hydrofluoric acid for $25 \mathrm{~min}$ at $100{ }^{\circ} \mathrm{C}$ (Group GBHF). The highest surface roughness values and hydrophilicity were shown in Group HF and Group GBHF. Scanning electron microscopy (SEM) showed that hydrofluoric acid can create a crater-like appearance on the zirconia surface. An energy-dispersive X-ray (EDX) analysis demonstrated similar element concentration (wt \%) in Group C, Group HF, and Group GBHF, but not for Group GB with higher concentrations of $\mathrm{Al}$ and Si element. Colony forming unit (CFU) counts showed that a similar amount of $S$. sanguinis biofilm and significantly lower $P$. gingivalis biofilm were formed on zirconia surfaces in Group HF and Group GBHF compared to that in Group C after three days of bacteria culture $(p<0.05)$. These results indicate that hydrofluoric acid etching on zirconia may not increase $S$. sanguinis and $P$. gingivalis mature biofilm formation on zirconia.
\end{abstract}

Keywords: zirconia; hydrofluoric acid; surface topography; biofilm

\section{Introduction}

Dental implants and abutments are usually made of titanium due to its biocompatibility and mechanical properties. However, esthetic demand is more critical, especially in the anterior regions of the mouth. As a way to achieve optimal esthetics, zirconia $\left(\mathrm{ZrO}_{2}\right)$ ceramic restorations [1], abutments [2], and implants [3] have been attractive in dentistry due to their high biocompatibility, esthetic properties of white color, and outstanding mechanical properties [4].

Various works have been conducted on the development of zirconia surface characteristics to improve its properties [5]. Surface characteristics can influence bond strength of resin cements [6-12] and glazing ceramic [13] to zirconia prosthetics, osteointegration ability [14], bacteria [15,16], and candida [17] adhesion to zirconia abutment and implant surface. Although zirconia ceramic has an acid-resistant polycrystalline structure, it has been found that zirconia can be etched by hydrofluoric acid, such that the micro-morphological surface could be created by varying the concentration and 
etching time of hydrofluoric acid [11,18]. On the other hand, temperature also plays an important role in molecular motion and affects the chemical kinetics. Hot etchant is a promising approach for increasing the surface roughness of zirconia $[19,20]$. Liu et al. previously demonstrated using a $48 \%$ hydrofluoric acid solution at $100{ }^{\circ} \mathrm{C}$ for $25 \mathrm{~min}$ could create excellent three-dimensional networks at a nanometric scale that can increase resin to zirconia bond strength without phase transformation [11]. Therefore, it appears that the method of etching $\mathrm{ZrO}_{2}$ in hot hydrofluoric acid is deemed to be promising.

Dental plaque induces an inflammatory reaction, with possible progressive bone loss around implants. It is associated with periodontal disease and peri-implant disease [21,22]. Early colonization of bacteria is the initial step in the formation of biofilm, leading to the pathological process of infection [11]. Plaque accumulation depends on the properties of the implant abutment and screw surface [23]. The type of material and surface characteristics can help increase or reduce the bacterial attachment and biofilm formation [16,24]. Thus, materials used to manufacture implant abutments, e.g., zirconia and titanium, should inhibit bacteria colonization on their surface [25]. Although there was investigation shown promising results that the surface topographies of zirconia ceramic treated by hydrofluoric acid can improve resin bonding strength to zirconia ceramics [20] and promoting osseointegration [26], the response of biofilm formation on hydrofluoric acid-etched zirconia surfaces has not been investigated.

We want to investigate whether hydrofluoric acid-etched zirconia surface have a biological effect on zirconia surfaces, which may accelerate or inhibit biofilm formation on those surfaces. We should consider these effects before the application of hydrofluoric acid etching on zirconia surfaces. The objective of this study was to observe the effect of hydrofluoric acid etching treatment on zirconia surface topography and to detect the bacteria adhesion and biofilm formation on the zirconia surface after hydrofluoric acid etching treatment.

\section{Materials and Methods}

\subsection{Sample Preparation}

Commercially-available cylindrical zirconia blocks (Cercon base, Degu-Dent GmbH, Hanau, Germany) were used in this study. The zirconia blocks were cut into quarter circle specimens $(12.5 \mathrm{~mm}$ in radius and $1 \mathrm{~mm}$ in thickness) using a high-speed precision saw (IsoMet ${ }^{\mathrm{TM}}$ 5000, BUEHLER, Lake Bluff, IL, USA) with a diamond blade under running water. After being polished with 1000-grit $\mathrm{SiC}$ abrasive paper, the samples were then finally sintered according to the manufacturer's instruction. All the fully-sintered zirconia samples were ultrasonically cleansed in $70 \%$ ethanol solution for $15 \mathrm{~min}$, rinsed with de-ionized water, and air dried. They were randomly divided into four groups and treated with one of the following surface modification protocols:

(a) Group C (control group): No further modification treatment;

(b) Group GB: The zirconia samples were grit-blasting with $110 \mu \mathrm{m}$ silica-coated alumina particles (Rocatecs, 3M ESPE, Seefeld, Germany) at a constant pressure of 3.0 bar for $15 \mathrm{~s}$;

(c) Group HF: The zirconia samples were then treated with $40 \%$ hydrofluoric acid (FARCO, Hong Kong, China) for $25 \mathrm{~min}$ at $100{ }^{\circ} \mathrm{C}$, and then rinsed with deionized water for $60 \mathrm{~s}$ and air dried; and

(d) Group GBHF: Zirconia surface were treated with grit-blasting with $110 \mu \mathrm{m}$ silica-coated alumina particles (Rocatecs) at a constant pressure of 3.0 bar for $15 \mathrm{~s}$, then treated with $40 \%$ hydrofluoric acid for $25 \mathrm{~min}$ at $100{ }^{\circ} \mathrm{C}$, and rinsed with deionized water for $60 \mathrm{~s}$ and air dried.

\subsection{Surface Roughness}

Surface roughness $\left(R_{a}\right)$ values of zirconia samples in each group were measured with a profilometer (Surtronic 3+, Taylor-Hobson, Leicester, UK). $R_{a}$ value was chosen as the test parameter. The profilometer was set to measure at every $0.8 \mathrm{~mm}$ cut-off value. Three zirconia samples were tested for each group. Each zirconia sample was tested three times at different area of the sample and the average value of each group was calculated. 


\subsection{Contact Angle}

The contact angle values of the zirconia samples were assessed. The sessile drop method (DSA100Drop Shape Analyzer, KRÜSS, Germany) was used to determine the contact angle. Ultrapure type 1 water was used as probe-liquids. The distance between the tip of the burette and the zirconia surface was kept constant at $10 \mathrm{~mm}$. Photographs were taken after droplets impacted on the zirconia surface and would be in the most stable and measurable state [27]. The volume of each water drop was $1 \mu \mathrm{L}$. All specimens were read under normal laboratory atmospheric environment. Then, for each specimen, the contact angles were measured and calculated from three drops of the liquid droplets.

\subsection{Scanning Electron Microscopy (SEM) and Energy-Dispersive X-ray Spectroscopy (EDX)}

A scanning electron microscope (SU1510, HITACHI, Tokyo, Japan) was applied to observe the surface morphology of zirconia surfaces in different groups. The samples were gold sputtered. Five images were taken at random locations for each sample at the magnifications of $1000 \times$ and $2000 \times$. Energy dispersive X-ray spectroscopy (EDX) (IXRF 550i Systems, Austin, TX, USA) was used to analyze the elemental composition of zirconia surfaces with an operational voltage of $15 \mathrm{kV}$. Each specimen was measured at three different places.

\subsection{Bacterial Strains and Biofilm Formation}

The bacteria strains used in this study were S. sanguinis ATCC10566 and P. gingivalis ATCC33277. All biofilms were grown in 24-well microtitre plates (Corning, NY, USA) containing a zirconia sample in each well. The zirconia samples were placed at the bottom of the well with the tested surfaces upwards to allow biofilm grown on. The growth medium was dispensed as $1 \mathrm{~mL}$ per well in the 24-well microtitre plates.

To grow S. sanguinis biofilm, a final growth medium with $10^{7}$ bacteria $/ \mathrm{ml}$ in BHI was adjusted. The growth medium was refreshed every $24 \mathrm{~h}$ for $S$. sanguinis. To grow P. gingivalis biofilm, $10^{8}$ bacteria / $\mathrm{mL}$ in P. gingivalis broth (composed of $30 \mathrm{~g}$ Trypticase Soy Broth (TSB), $5 \mathrm{~g}$ yeast extract, $1 \mathrm{~L}$ distilled water, and $10 \mathrm{~mL}$ hemin/vitamin $\mathrm{K}$ stock solution) was adjusted. The biofilms were grown under anaerobic condition $\left(85 \% \mathrm{~N}_{2}, 10 \% \mathrm{H}_{2}, 5 \% \mathrm{CO}_{2}\right)$ at $37^{\circ} \mathrm{C}$. The $S$. sanguinis and $P$. gingivalis biofilms formation was evaluated after 1 day and 3 days incubation.

\subsection{Quantification of Biofilm Formation}

Biofilm collection was conducted at time points of day 1 and day 3, the zirconia discs with biofilms were rinsed once in phosphate-buffered saline solution (PBS, composed of $8.0 \mathrm{~g} \mathrm{NaCl}, 0.2 \mathrm{~g}$ $\mathrm{KCl}, 1.0 \mathrm{~g} \mathrm{Na}_{2} \mathrm{HPO}_{4}$, and $0.2 \mathrm{~g} \mathrm{KH}_{2} \mathrm{PO}_{4}$ per litre, adjusted to $\mathrm{pH}$ 7.4) and transferred into a sterilized tube containing $1 \mathrm{~mL}$ of growing broth. The biofilms were removed from the discs and dispersed by vortexing for $30 \mathrm{~s}$. Serially-diluted samples were plated on blood agar plates. The plates were incubated anaerobically at $37^{\circ} \mathrm{C}$ for two days for S. sanguinis and seven days for P. gingivalis. Then the colonies of bacteria were counted. Total numbers of bacteria were determined by serial dilutions on blood agar plates. The plates were incubated at $37^{\circ} \mathrm{C}$ for two days for S. sanguinis and seven days for $P$. gingivalis. The number of colony forming units (CFU) at each dilution rate was counted after incubation and the average $\mathrm{CFU} / \mathrm{mL}$ was determined. The total numbers of bacteria were calculated based on dilution.

\subsection{Statistical Analysis}

Data were analyzed with the Statistical Package for Social Science (SPSS ${ }^{\circledR}$, Version 23, IBM, Armonk, NY, USA). The CFU counts were log-transformed before the statistical tests. The data after $\log$ transformation was verified to be a normal distribution. One-way analysis of variance (ANOVA) using Tukey's post hoc test was applied to compare between different groups at the significance of 0.05 . 


\section{Results}

\subsection{Surface Roughness}

The $R_{a}$ values obtained within each group are shown in Table 1 . Twenty specimens were used for surface roughness test (five for each group). The lowest mean surface roughness value $\left(R_{a}=0.17 \pm 0.03 \mu \mathrm{m}\right)$ was found in the control group and it was significantly lower than all of the other three groups. The surface roughness value of group GB $\left(R_{a}=0.56 \pm 0.05 \mu \mathrm{m}\right)$ was at the medium level in all of the four groups and it was significantly higher than the control group. Group HF $\left(R_{a}=1.47 \pm 0.04 \mu \mathrm{m}\right)$ and Group GBHF $\left(R_{a}=1.49 \pm 0.05 \mu \mathrm{m}\right)$ exhibited statistically higher values of surface roughness than the other two group $(p<0.05)$ but there was no significant difference between these two groups $(p>0.05)$.

\subsection{Contact Angle}

The changes in contact angles of water on zirconia surfaces in different groups after different treatments are shown in Table 1. Twenty specimens were used for contact angle testing (five for each group). The contact angle of zirconia surfaces in Group HF and Group GBHF decreased after treatment $(p<0.05)$, while increasing slightly in Group GB, but the difference was not significant $(p>0.05)$.

Table 1. Surface roughness $\left(R_{a}\right)(n=20)$ and water contact angle $(\theta)(n=20)$ of different groups (mean \pm standard deviation).

\begin{tabular}{cccc}
\hline Group & Surface Treatment & Surface Roughness $(\mu \mathrm{m})$ & Water Contact Angle $(\theta)^{\circ}$ \\
\hline Group C & Control & $0.17 \pm 0.03^{\mathrm{a}}$ & $100.24 \pm 2.49^{\mathrm{d}}$ \\
\hline Group GB & Grit-blasting & $0.56 \pm 0.05^{\mathrm{b}}$ & $109.87 \pm 8.22^{\mathrm{d}}$ \\
\hline Group HF & Etching with hydrofluoric acid & $1.47 \pm 0.04^{\mathrm{c}}$ & $79.13 \pm 5.20^{\mathrm{e}}$ \\
\hline Group GBHF & $\begin{array}{c}\text { Grit-blasting and then etching } \\
\text { with hydrofluoric acid }\end{array}$ & $1.48 \pm 0.05^{\mathrm{c}}$ & $81.35 \pm 1.15^{\mathrm{e}}$ \\
\hline
\end{tabular}

Note: Different superscripts a, b, c, d, e, denote significant differences between groups $(\alpha=0.05)$.

\subsection{Scanning Electron Microscopy (SEM)}

SEM images (Figure 1) showed the morphological appearance of zirconia surfaces after different treatments from each group. In Group C, the zirconia surface appeared to be smooth and flat with some small pits and shallow grooves produced by the polishing procedure. In Group GB, the method generated some small flaws and granules on the surface. The treatment of hydrofluoric acid etching in Group HF tended to produce porous structures and made the zirconia surface form with many craters with various dimensions. The treatment of grit-blasting first and then etching with hydrofluoric acid in Group GBHF made the zirconia surface appearance similar with that in the Group HF. The close-up images for Group HF and Group GBHF are shown in Figure 2, showing that there were some sharp spiky edges created by the hydrofluoric acid etching.
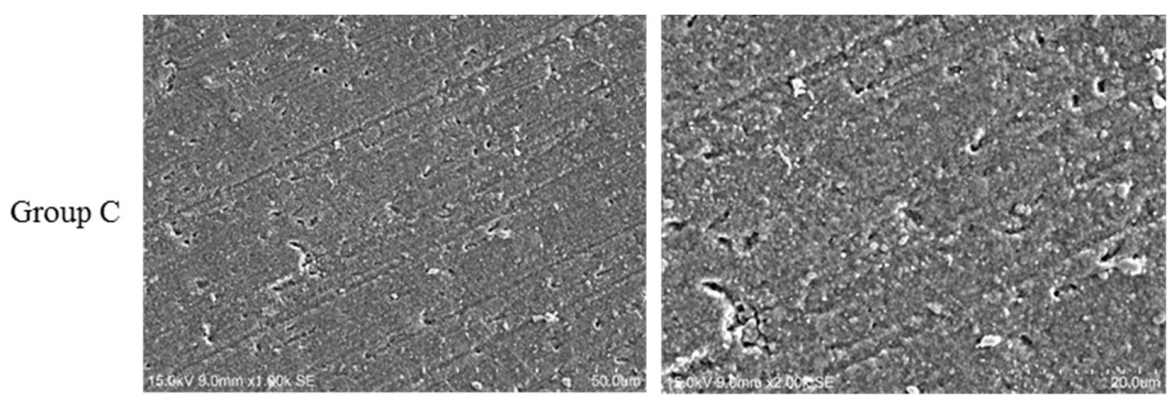

Figure 1. Cont. 


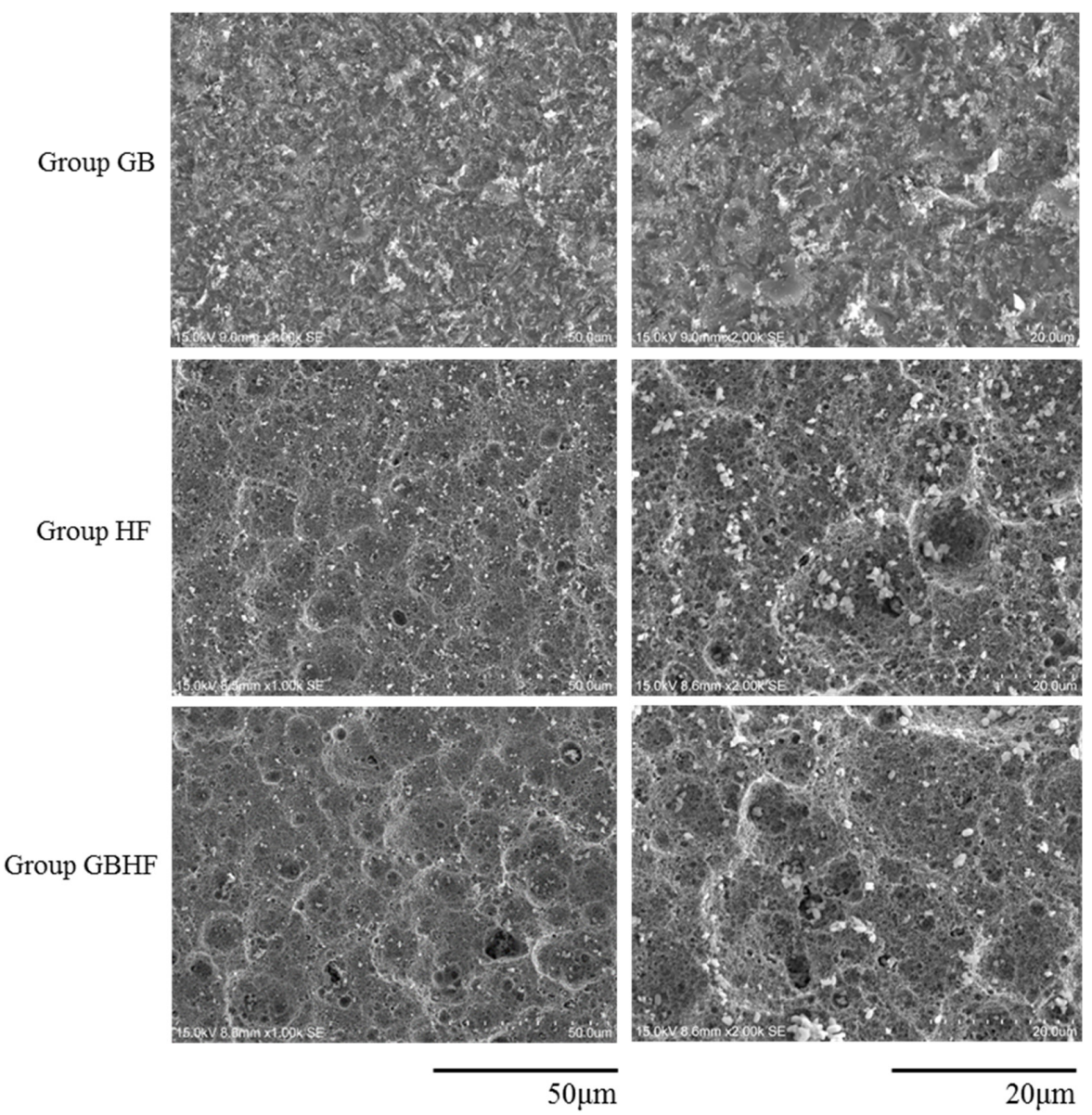

Figure 1. SEM images of various zirconia surfaces at the magnification of $1000 \times$ and $2000 \times$.

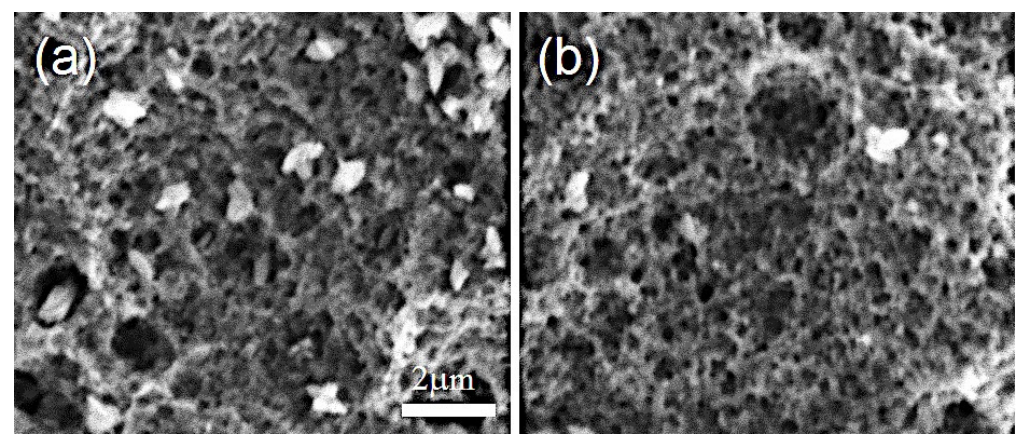

Figure 2. Close up SEM images from Figure 1 (captured from the images at the magnification of $2000 \times$ under SEM). (a) Group HF; and (b) Group GBHF. Note the sharp spikes of the surface.

\subsection{Energy-Dispersive X-ray Spectroscopy (EDX)}

Table 2 shows the EDX analysis of the zirconia surfaces after different surface treatments. The EDX showed high concentration ( $w \mathrm{t} \%$ ) of $\mathrm{Zr}$ and $\mathrm{O}$ in all the four groups. High concentration (wt \%) of $\mathrm{Al}$ and $\mathrm{Si}$ are also obviously shown in Group GB. There was no peak for the fluorine in all the spectra of zirconia samples, which clearly indicated the absence of fluorine in all the groups, particularly Group HF and Group GBHF. It was demonstrated in the elemental concentration analysis that the concentration ( $\mathrm{wt} \%$ ) of element composition seemed to be similar in Group C, Group HF, and Group GBHF. However, there was an increase in the concentration (wt \%) of $\mathrm{Al}(3.768 \%), \mathrm{Si}(4.674 \%)$, and O $(16.363 \%)$ in Group GB. 
Table 2. Elemental composition of zirconia surfaces after different surface treatments by EDX.

\begin{tabular}{ccccc}
\hline Element Conc (wt \%) & Group C & Group GB & Group HF & Group GBHF \\
\hline O & 10.606 & 16.363 & 10.098 & 10.675 \\
Al & 1.591 & 3.768 & 1.603 & 1.605 \\
Si & 0.199 & 4.674 & 0.057 & 0.236 \\
Y & 8.686 & 6.014 & 8.955 & 8.297 \\
Zr & 78.918 & 69.182 & 79.287 & 79.189 \\
\hline Total & 100.000 & 100.000 & 100.000 & 100.000 \\
\hline
\end{tabular}

\subsection{Biofilm Formation}

The CFU method was used to calculate the number of bacterial cells adhered to the zirconia surfaces after incubation. Figure 3 shows the $\log$ transformed CFU counts of $S$. sanguinis and P. gingivalis biofilms between different groups of zirconia surfaces on day 1 and day 3. For both bacterial species, the speed of the biofilm formation was the highest during the first day. The average increases of CFU counts from the first day were significantly higher than those from 1 day to 3 days, irrespective of the properties of zirconia surfaces and the bacterial species. For S. sanguinis biofilm in Group GB and Group GBHF, there were no increases in biofilm formation from day 1 to day $3(p>0.05)$. For $P$. gingivalis biofilm in Group HF and Group GBHF, no significant increase was found in biofilm formation from day 1 to day $3(p>0.05)$.
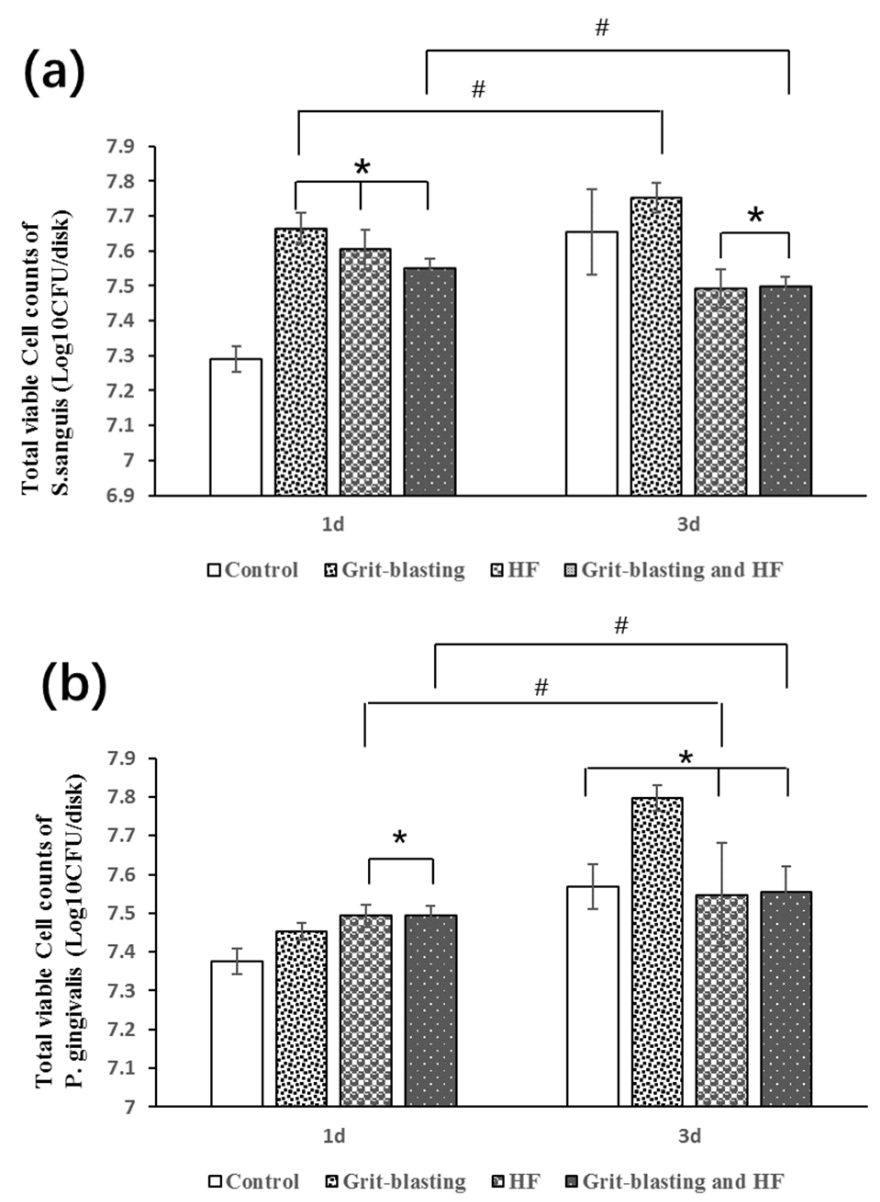

Figure 3. Changes of total viable CFU counts at the time point of day 1 and day 3 in biofilms: (a) S. sanguinis and (b) P. gingivalis. * denotes no statistically significant $(p>0.05)$ difference between different groups among the same time point; \# denotes no statistical significant difference $(p>0.05)$ between the same groups among different time points. 
For S. sanguinis biofilm on day 1 (Figure 3a), the CFU counts of Group GB, Group HF, and Group GBHF were significantly higher than that of Group C $(p<0.05)$, while there was no significant difference between these three groups $(p>0.05)$. However, when the time went on to day 3 , significant lower CFU counts were found in Group HF and Group GBHF compared to Group C and Group GB, while no significant difference was found between Group HF and Group GBHF ( $p>0.05)$. On the other hand, for $P$. gingivalis biofilm (Figure $3 b$ ), when the total CFU counts were relatively low on day 1 , the number of $P$. gingivalis bacterial found on zirconia surfaces in Group HF and Group GBHF was highest while that in Group C was lowest $(p<0.05)$. On day 3, no significant differences in CFU counts were observed between Group C, Group HF, and Group GBHF ( $p>0.05)$, and the CFU counts of these three groups were significantly lower than that in Group GB.

\section{Discussion}

In the present study, we modified zirconia surfaces with grit blasting and hot hydrofluoric acid etching treatment. S. sanguinis and P. gingivalis were used to evaluate their biological response to zirconia surfaces. Statistically significant increases of surface roughness were found after various surface treatments, such that a greater increase of surface roughness of zirconia surfaces in Group HF and Group GBHF compared to Group C and Group GB. This finding is consistent with the previous studies which revealed that grit blasting and hydrofluoric acid etching can increase the surface roughness of zirconia $[18,26]$. In addition, the water contact angle of zirconia surfaces was measured in our study, which can reflect the changes in hydrophilicity and hydrophobicity. It was observed that the water contact angle increased slightly in Group GB and decreased significantly in Group HF and Group GBHF, i.e., zirconia surfaces in Group HF and Group GBHF were more hydrophilic compared to that in the control group, whilst zirconia surfaces in Group GB were more hydrophobic compared to that in the control group.

SEM figures presented different topography after different treatments compared to the control group. On the surface of zirconia in Group GB, a typical grit-blasted surface was observed. In EDX analysis, the high peaks of $\mathrm{Al}$ and $\mathrm{Si}$ in Group GB may be attributed to the silica-coated alumina particles. Hydrofluoric acid etching groups (Group HF and Group GBHF) produced porous structures that craters and spiky clusters were observed on the etched zirconia surfaces. However, no F element was detected in Group HF and Group GBHF by EDX. This finding was inconsistent with a previous study by Xie et al. [28], which claimed some F-containing compounds were found by X-ray diffraction (XRD) and EDX. Indeed, in their analysis, they have not tested directly from the HF-etched zirconia surface, but the surface of the sediments in the HF solutions. These sediments were produced during the etching process and they were the reaction products with HF, which did not mean they carry the same chemical entities as the zirconia surface. The XRD matching from their graph is also primitive, such that not all peaks could be properly identified. Thus, their study is not comparable to us.

The adhesion of bacteria is generally influenced by the material surface characteristics, including surface roughness, surface free energy, surface chemistry, and surface topography $[29,30]$. S. sanguinis was recognized as a pioneer colonizer bacteria and its colonization can prepare favorable environment for later colonizers [15]. P. gingivalis, featuring predominantly anaerobic Gram-negative bacteria, was confirmed to have a high positive relationship with peri-implantitis [31]. Therefore, these two representative bacteria were chosen in our study.

In the current study, at early stage of day 1 , biofilm formation of both species on zirconia surfaces in Group HF and Group GBHF were highest among all four groups, this may be attributed to the high surface roughness of these two groups. In fact, various studies have indicated a higher $R_{a}$ value $\left(R_{a}>0.2 \mu \mathrm{m}\right)$ could be associated with increased bacteria accumulation at the initial bacteria adhesion stage [11,22]. However, when the time went on to day 3, CFU counts of both species of biofilms appeared the lowest in Group HF and Group GBHF. Thus, when the biofilm become mature, the surface roughness seemed to be not the predominate factor that influenced bacteria initial adhesion. 
This is consistent with previous studies which emphasized that the influence of surface roughness was diminished when the biofilm becomes mature [22,32] on different materials.

The biofilms formation of $S$. sanguinis and P. gingivalis on day 3 in our study may be explained by the contact angle results and surface topography since both of them are important factors for bacterial adhesion [15]. Das et al. investigated that the maturation adhesion of Streptococcus and Actinomyces strains were in positive relationship with an increase in surface hydrophobicity [33]. The underlying reason may be the fact that increased proteins accumulate on hydrophobic surfaces, which serving as specific binding sites for bacteria, subsequently accelerating and facilitating bacterial adhesion [32]. As observed in our study, the hydrophobicity of zirconia surface was lowest in Group HF and Group GBHF. This may be one of the reasons which can be responsible for the lowest biofilms formation for both bacteria on day 3 in Group HF and Group GBHF.

Interestingly, we observed that CFU of S. sanguinis in Group HF decreased at day 3. Since the formation of a biofilm is a dynamic complex process, it usually occurs in four main stages: (1) bacterial attachment to a surface, (2) microcolony formation, (3) biofilm maturation, and (4) detachment of bacteria which may then colonize new areas [22]. In our study, it was assumed that $S$. sanguinis grow in a very high speed during the first day and $\log _{10} \mathrm{CFU} /$ disk has been almost 7.6 in one-day biofilm. This high growth speed might lead to the full coverage of biofilm on the zirconia surface, and as time went on, there was no extra space for new bacteria attachment, while dead bacteria started to accumulate in the biofilm on the zirconia surface. Therefore, we observed CFU counts of S. sanguinis in Group HF decreased at day 3, since the method of CFU counts can only detect live bacteria.

Surface texture and topography also play important roles in microbial adhesion [22,32]. Many micrometer- and nanometer-scale topographic patterns with varying shape and size have been shown to inhibit biofilm formation compared to flat surfaces of the same material $[29,34]$. It was concluded by Perera et al. that microtopographic surface patterns represent a promising approach to inhibit bacterial adhesion and biofilm formation, since they found protruding and receding squares, circles, and parallel channels on their material provoked a significant reduction in bacterial adhesion relative to the smooth control samples [35]. Previous study has shown the grit-blasting and hydrofluoric acid etching could create nano-scale topography on zirconia surfaces [26]. Another study [11] used a hot HF solution to $100{ }^{\circ} \mathrm{C}$ could remove zirconia surface grains unevenly instead of a uniform disposal of the surface layer, such that a surface with holes and pits of various sizes, exposed with sharp and spiky surface (Figure 2) as revealed in this study, could be formed. This type of uneven surface may inhibit bacteria attachment, since bacteria ranged in size from 0.2 to $5 \mu \mathrm{m}$ and these various sizes of holes and pits may not allow a favorable environment for bacteria attachment [36], needless to say the sharp spiky surfaces could shred the bacteria, which would have a certain physical anti-bacteria effect [34]. Therefore, the special surface topography of the zirconia surfaces in Group HF and Group GBHF may have a negative effect on bacteria attachment and inhibit biofilm formation.

A previous study found that biofilms formation on titanium surfaces depend on not only the surface topography, but also the bacteria species involved [37]. In this study, different situations of S. sanguinis and P. gingivalis bacteria adhesion were demonstrated on zirconia surfaces. In addition, we did not find any difference between zirconia surfaces in Group HF and Group GBHF in our study, no matter in the aspect of physicochemical properties of the surface or the biofilm formation. The underlying reason may be due to the strong etching ability of hydrofluoric acid and it eroded all the effects of grit-blasting treatment on zirconia surfaces.

A further study is required to evaluate mixed-species bacterial biofilm adhesion on hydrofluoric acid-etched zirconia surfaces to show exactly what happens when a complex and natural microbiota combines with zirconia material to simulate the oral environment. 


\section{Conclusions}

In conclusion, hydrofluoric acid etching changed the surface topography of zirconia surfaces. The application of $40 \%$ hydrofluoric acid for $25 \mathrm{~min}$ at $100{ }^{\circ} \mathrm{C}$ increased the surface roughness and wettability of zirconia surface used in our study, and inhibited S. sanguinis and P. gingivalis bacteria adhesion and biofilm formation on zirconia. Further study is necessary to determine whether this was due to topographical changes of zirconia induced by hydrofluoric acid etching. The creation of crater-like topographies on the surface of zirconia by hydrofluoric acid offers a promising method for inhibiting the bacteria adhesion and biofilm formation on zirconia.

Acknowledgments: This work was supported by National Natural Science Foundation of China (81470783, 81600914) and the Natural Science Foundation of Guangdong Province (2015A 030311051, 2016A030310173). This work was done in partial fulfilment of the requirements of the degree of Doctor of Philosophy for the first author at the Faculty of Dentistry, The University of Hong Kong.

Author Contributions: Aifang Han and James K.-H. Tsoi conceived and designed the experiments; Aifang Han performed the experiments; Aifang Han and James K.-H. Tsoi analyzed the data; James K.-H. Tsoi, Zhuofan Chen, and Jukka P. Matinlinna contributed reagents/materials/analysis tools; Aifang Han, James K.-H. Tsoi, Zhuofan Chen, and Jukka P. Matinlinna wrote the paper.

Conflicts of Interest: The authors declare no conflict of interest.

\section{References}

1. Vichi, A.; Louca, C.; Corciolani, G.; Ferrari, M. Color related to ceramic and zirconia restorations: A review. Dent. Mater. 2011, 27, 97-108. [CrossRef] [PubMed]

2. Linkevicius, T.; Vaitelis, J. The effect of zirconia or titanium as abutment material on soft peri-implant tissues: A systematic review and meta-analysis. Clin. Oral Implants Res. 2015, 26, 139-147. [CrossRef] [PubMed]

3. Van Eric Dooren, D.; Calamita, M.; Calgaro, M.; Coachman, C.; Ferencz, J.L.; Silva, N.R. Mechanical, biological and clinical aspects of zirconia implants. Eur. J. Esthet. Dent. 2012, 7, 396-417.

4. Hashim, D.; Cionca, N.; Courvoisier, D.S.; Mombelli, A. A systematic review of the clinical survival of zirconia implants. Clin. Oral Investig. 2016, 20, 1403-1417. [CrossRef] [PubMed]

5. Siwen, L.; Shishi, L.; Yanhong, W.; Hongmei, M. Effects of different surface modifications on micro-structure and adhesion of zirconia ceramic: An in vitro study. West China J. Stomatol. 2017, 35, 43-50.

6. Ito, Y.; Okawa, T.; Fukumoto, T.; Tsurumi, A.; Tatsuta, M.; Fujii, T.; Tanaka, J.; Tanaka, M. Influence of atmospheric pressure low-temperature plasma treatment on the shear bond strength between zirconia and resin cement. J. Prosthodont. Res. 2016, 60, 289-293. [CrossRef] [PubMed]

7. Yilmaz-Savas, T.; Demir, N.; Ozturk, A.N.; Kilic, H.S. Effect of different surface treatments on the bond strength of lithium disilicate ceramic to the zirconia core. Photomed. Laser Surg. 2016, 34, 236-243. [CrossRef] [PubMed]

8. Cheng, H.C.K.; Tsoi, J.K.H.; Zwahlen, R.A.; Matinlinna, J.P. Effects of silica-coating and a zirconate coupling agent on shear bond strength of flowable resin-zirconia bonding. Int. J. Adhes. Adhes. 2014, 50, 11-16. [CrossRef]

9. Ho, B.J.; Tsoi, J.K.H.; Liu, D.; Lung, C.Y.K.; Wong, H.M.; Matinlinna, J.P. Effects of sandblasting distance and angles on resin cement bonding to zirconia and titanium. Int. J. Adhes. Adhes. 2015, 62, 25-31. [CrossRef]

10. Liu, D.; Pow, E.H.N.; Tsoi, J.K.H.; Matinlinna, J.P. Evaluation of four surface coating treatments for resin to zirconia bonding. J. Mech. Behav. Biomed. 2014, 32, 300-309. [CrossRef] [PubMed]

11. Liu, D.; Tsoi, J.K.-H.; Matinlinna, J.P.; Wong, H.M. Effects of some chemical surface modifications on resin zirconia adhesion. J. Mech. Behav. Biomed. 2015, 46, 23-30. [CrossRef] [PubMed]

12. Matinlinna, J.P.; Choi, A.H.; Tsoi, J.K.H. Bonding promotion of resin composite to silica-coated zirconia implant surface using a novel silane system. Clin. Oral Implants Res. 2013, 24, 290-296. [CrossRef] [PubMed]

13. Liu, D.; Matinlinna, J.P.; Tsoi, J.K.H.; Pow, E.H.N.; Miyazaki, T.; Shibata, Y.; Kan, C.W. A new modified laser pretreatment for porcelain zirconia bonding. Dent. Mater. 2013, 29, 559-565. [CrossRef] [PubMed]

14. Kohal, R.J.; Bächle, M.; Att, W.; Chaar, S.; Altmann, B.; Renz, A.; Butz, F. Osteoblast and bone tissue response to surface modified zirconia and titanium implant materials. Dent. Mater. 2013, 29, 763-776. [CrossRef] [PubMed] 
15. Al-Radha, A.S.D.; Dymock, D.; Younes, C.; O'Sullivan, D. Surface properties of titanium and zirconia dental implant materials and their effect on bacterial adhesion. J. Dent. 2012, 40, 146-153. [CrossRef] [PubMed]

16. De Avila, E.D.; Avila-Campos, M.J.; Vergani, C.E.; Spolidório, D.M.P.; de Assis Mollo, F., Jr. Structural and quantitative analysis of a mature anaerobic biofilm on different implant abutment surfaces. J. Prosthet. Dent. 2016, 115, 428-436. [CrossRef] [PubMed]

17. Villard, N.; Seneviratne, C.; Tsoi, J.K.H.; Heinonen, M.; Matinlinna, J. Candida albicans aspects of novel silane system-coated titanium and zirconia implant surfaces. Clin. Oral Implants Res. 2015, 26, 332-341. [CrossRef] [PubMed]

18. Smielak, B.; Klimek, L. Effect of hydrofluoric acid concentration and etching duration on select surface roughness parameters for zirconia. J. Prosthet. Dent. 2015, 113, 596-602. [CrossRef] [PubMed]

19. Ho, G.W.; Matinlinna, J.P. Evaluation of the microtensile bond strength between resin composite and hydrofluoric acid etched ceramic in different storage media. J. Adhes. Sci. Technol. 2011, 25, 2671-2685. [CrossRef]

20. Xie, H.; Chen, C.; Dai, W.; Chen, G.; Zhang, F. In vitro short-term bonding performance of zirconia treated with hot acid etching and primer conditioning. Dent. Mater. J. 2013, 32, 928-938. [CrossRef] [PubMed]

21. Karande, A.M.; Vergeese, C.S.; Khandeparkar, R.; Mahajan, T. Inter relationship between the implant and biofilm based on their microbial linkage. J. Adv. Med. Dent. Sci. Res. 2017, 5, 46-53.

22. Han, A.F.; Tsoi, J.K.H.; Rodrigues, F.P.; Leprince, J.G.; Palin, W.M. Bacterial adhesion mechanisms on dental implant surfaces and the influencing factors. Int. J. Adhes. Adhes. 2016, 69, 58-71. [CrossRef]

23. Kumar, Y.; Jain, V.; Chauhan, S.S.; Bharate, V.; Koli, D.; Kumar, M. Influence of different forms and materials (zirconia or titanium) of abutments in periimplant soft-tissue healing using matrix metalloproteinase-8: A randomized pilot study. J. Prosthet. Dent. 2017. [CrossRef] [PubMed]

24. Do Nascimento, C.; Pita, M.S.; de Souza Santos, E.; Monesi, N.; Pedrazzi, V.; de Albuquerque Junior, R.F.; Ribeiro, R.F. Microbiome of titanium and zirconia dental implants abutments. Dent. Mater. 2016, 32, 93-101. [CrossRef] [PubMed]

25. De Avila, E.D.; Vergani, C.E.; Junior, F.A.M.; Junior, M.J.; Shi, W.; Lux, R. Effect of titanium and zirconia dental implant abutments on a cultivable polymicrobial saliva community. J. Prosthet. Dent. 2017. [CrossRef] [PubMed]

26. Hiroshi, I.; Sasaki, H.; Saito, K.; Honma, S.; Yajima, Y.; Yoshinari, M. Response of osteoblast-like cells to zirconia with different surface topography. Dent. Mater. J. 2013, 32, 122-129.

27. Ruiz-Cabello, F.M.; Rodríguez-Valverde, M.; Cabrerizo-Vílchez, M. Equilibrium contact angle or the most-stable contact angle? Adv. Colloid Interface Sci. 2014, 206, 320-327. [CrossRef] [PubMed]

28. Xie, H.; Shen, S.; Qian, M.; Zhang, F.; Chen, C.; Tay, F.R. Effects of acid treatment on dental zirconia: An in vitro study. PLoS ONE 2015, 10, e0136263. [CrossRef] [PubMed]

29. Song, F.; Koo, H.; Ren, D. Effects of material properties on bacterial adhesion and biofilm formation. J. Dent. Res. 2015, 94, 1027-1034. [CrossRef] [PubMed]

30. Teughels, W.; Van Assche, N.; Sliepen, I.; Quirynen, M. Effect of material characteristics and/or surface topography on biofilm development. Clin. Oral Implants Res. 2006, 17, 68-81. [CrossRef] [PubMed]

31. Pérez-Chaparro, P.J.; Duarte, P.M.; Shibli, J.A.; Montenegro, S.; Lacerda Heluy, S.; Figueiredo, L.C.; Faveri, M.; Feres, M. The current weight of evidence of the microbiologic profile associated with peri-implantitis: A systematic review. J. Periodontol. 2016, 87, 1295-1304. [CrossRef] [PubMed]

32. Al-Ahmad, A.; Wiedmann-Al-Ahmad, M.; Fackler, A.; Follo, M.; Hellwig, E.; Bächle, M.; Hannig, C.; Han, J.-S.; Wolkewitz, M.; Kohal, R. In vivo study of the initial bacterial adhesion on different implant materials. Arch. Oral Biol. 2013, 58, 1139-1147. [CrossRef] [PubMed]

33. Das, T.; Sharma, P.K.; Busscher, H.J.; van der Mei, H.C.; Krom, B.P. Role of extracellular DNA in initial bacterial adhesion and surface aggregation. Appl. Environ. Microbiol. 2010, 76, 3405-3408. [CrossRef] [PubMed]

34. Li, X.; Cheung, G.S.; Watson, G.S.; Watson, J.A.; Lin, S.; Schwarzkopf, L.; Green, D.W. The nanotipped hairs of gecko skin and biotemplated replicas impair and/or kill pathogenic bacteria with high efficiency. Nanoscale 2016, 8, 18860-18869. [CrossRef] [PubMed]

35. Perera-Costa, D.; Bruque, J.M.; González-Martín, M.L.; Gómez-García, A.C.; Vadillo-Rodríguez, V. Studying the influence of surface topography on bacterial adhesion using spatially organized microtopographic surface patterns. Langmuir 2014, 30, 4633-4641. [CrossRef] [PubMed] 
36. Smith, N.A.; Turkyilmaz, I. Evaluation of the sealing capability of implants to titanium and zirconia abutments against porphyromonas gingivalis, prevotella intermedia, and fusobacterium nucleatum under different screw torque values. J. Prosthet. Dent. 2014, 112, 561-567. [CrossRef] [PubMed]

37. Pita, P.P.C.; Rodrigues, J.A.; Ota-Tsuzuki, C.; Miato, T.F.; Zenobio, E.G.; Giro, G.; Figueiredo, L.C.; Gonçalves, C.; Gehrke, S.A.; Cassoni, A. Oral streptococci biofilm formation on different implant surface topographies. BioMed Res. Int. 2015, 2015, 159625. [CrossRef] [PubMed] 